\title{
College Students with Disabilities Explain Challenges Encountered in Professional Preparation Programs
}

\author{
Maureen E. Squires \\ SUNY Plattsburgh \\ Brad Countermine \\ SUNY Plattsburgh \& Beekmantown High School
}

\begin{abstract}
Throughout the United States, students with disabilities (SWD) are entering higher education in greater numbers than in the past; they also encounter barriers that negatively impact their college experience. This qualitative study explores the challenges of SWD at a public comprehensive college in the northeastern United States. Our research questions include the following: What are the internal and external challenges of college SWD in professional preparation programs? What might this mean for practice in higher education? In total, 541 participants completed an open-ended survey. Of this group, 45 participants disclosed having a disability, and 12 participated in follow-up interviews. Primary themes that emerged from this study include underdeveloped self-determination skills, lack of understanding (by SWD and faculty), the stigma associated with disabilities, and ineffective accommodations and support services. What follows is a review of relevant literature, discussion of findings, and presentation of implications for college SWD and professionals in higher education.
\end{abstract}

Throughout the United States, attendance of students with disabilities (SWD) at colleges and universities has significantly increased in the past few decades (Agarwal, Moya, Yasui, \& Seymour, 2015; Barnard-Brak, Sulak, Tate, \& Lechtenberger, 2010; Cawthon \& Cole, 2010; Garrison-Wade, 2012; Getzel \& Thoma, 2008; Hong, 2015; Lightner, Kipps-Vaughan, Schulte, \& Trice, 2012; Sniatecki, Perry, \& Snell, 2015; Stein, 2013). Federal civil rights legislation such as the Americans with Disabilities Act (ADA) and the 
Rehabilitation Act of 1973 (Section 504), designed to protect individuals with disabilities, has contributed to this process. These laws, which apply to education systems among other organizations, prohibit discrimination based on disability status and entitle individuals with disabilities to equal opportunities, equal access, and accommodations that level the playing field with their non-disabled peers (Cawthon \& Cole, 2010; Squires, 2015).

Yet even with such legislation, SWD continue to encounter internal (emerging from within the individual) and external (originating outside the individual) challenges that negatively impact their college experience. As compared to students without disabilities, SWD earn lower GPAs, take longer to graduate, and experience higher dropout rates (Agarwal et al., 2015; Garrison-Wade, 2012; Getzel \& Thoma, 2008; Hong, 2015; Lightner et al., 2012). The challenges SWD face in college profoundly disadvantage them. This study uses survey and interview data to explore the challenges encountered by SWD at a public comprehensive college in the northeastern United States. After reviewing salient barriers presented in the literature, we then present the findings and discuss implications for both college SWD and institutions of higher education.

\section{Literature Review}

College can be challenging for all students. For some young adults, it is their first time away from friends and family (support systems), their first experience with substantial autonomy (over schedules, leisure activities, and finances), or their first encounter with a new academic and social environment. College SWD face these challenges and potentially additional barriers. As members of a learning community, SWD both act on and are affected by institutions of higher education. They bring their own strengths and needs. Some of these needs (e.g., lacking requisite knowledge, skills, or dispositions for success in their major) may limit academic achievement. Institutions may also inadvertently hinder the success of college SWD through unclear or uncommunicated policies. What follows is a review of major internal and external barriers reported by college SWD.

\section{Internal Challenges}

Many college SWD encounter internal challenges that, if left unaddressed, can impede their academic success. Three themes will be discussed here. These include (a) lack of knowledge, including self-awareness and awareness of support services; (b) lack of self-determination skills; and (c) identity issues.

Lack of knowledge. Lack of knowledge encompasses several areas. Numerous SWD do not have a deep understanding of who they are, their abilities, or how to address

their limitations. Studies have indicated that many college SWD are unable to describe their disability (Barnard-Brak et al., 2010; Marshak, Van Wieren, Ferrell, Swiss, \& Dugan, 2010; Summers, White, Zhang, \& Gordon, 2014), cannot identify their diagnosed disability or the method by which they were diagnosed (Cawthon \& Cole, 2010; Marshak et al., 2010; Summers et al., 2014), cannot explain the disability's impact on their lives (Barnard-Brak et al., 2010; Hong, 2015; Marshak et al., 2010; Summers, et al., 2014), cannot describe their strengths and needs (Garrison-Wade, 2012), or are unaware of 
whether they had an Individualized Education Plan (IEP) or of the specific information it contained (Cawthon \& Cole, 2010; Lightner et al., 2012; Summers et al., 2014).

Lack of knowledge about the right to accommodations in college can limit the success of SWD. As mentioned previously, several federal laws serve to protect the rights of individuals with disabilities. Not all laws, however, apply in college. SWD who received services prior to college did so through an IEP under the Individuals with Disabilities Education Act of 1990 (IDEA) or a 504 Plan under Section 504 of the Rehabilitation Act of 1973. Section 504 is not age restrictive; IDEA is. IDEA pertains to children and youth from birth to age 21 who receive early intervention services or special education and related services in primary and secondary schools (U.S. Department of Education, n.d.). IDEA and its accompanying IEP does not apply to college students. In the K-12 setting, students' rights are protected by IDEA, and it is the district's responsibility to comply. In higher education, it is the student's responsibility to selfidentify and advocate for accommodations.

Lack of awareness about available services and lack of knowledge regarding how to access services in post-secondary institutions can adversely affect college SWD. In one study, nearly half of the college undergraduate students who completed the survey reported that they:

received no guidance on who to contact in the OSD [Office for Students with Disabilities] at their university, what accommodations or services they may need from their university, how to document their disability for their university, or discuss their most recent evaluation. (Cawthon \& Cole, 2010, p. 123)

Cawthon and Cole (2010) continued, "This indicates that SLD [students with learning disabilities] are potentially underprepared to locate services, obtain services, and advocate for services once they reach college" (p. 124). Marshak et al. (2010) found five barriers to pursuing and using disability services in college (p. 156). Confusion about disability services was a sub-theme of insufficient knowledge (one of the reported barriers). Some participants indicated that "they did not know specific services existed or that they did not know how to access the services" (p. 156). Such confusion was echoed in Lightner et al.'s (2012) study, in which lack of knowledge surfaced as a major theme. Several participants (particularly those who sought assistance from the Office of Disability Services after their first year) stated that they were unaware of the range of disability services provided, did not realize they had to initiate services themselves or at the Office of Disability Services, or lacked knowledge about the logistics of being evaluated (Lightner et al., 2012).

Having knowledge about available services on campus can positively impact postsecondary students' experience. Specifically, such knowledge allows college SWD to obtain the support they need to be academically successful and to stay in college. Part of this information includes how to access reasonable accommodations and the importance of forming relationships with faculty (Getzel \& Thoma, 2008). These are just a few of the essential self-advocacy and self-determination skills connected to success.

Lack of self-determination skills. Numerous definitions of self-determination exist. Field, Sarver, and Shaw (2003) defined self-determination as "a combination of skills, knowledge and beliefs that enable a person to engage in goal-directed, self-regulated, 
autonomous behavior" (p. 339). Self-determination is a liberatory practice whereby individuals with disabilities are active agents in and of their lives. It includes a myriad of skills, such as "decision-making, problem solving, goal setting and attainment, selfregulation, leadership, perceptions of control, efficacy expectations, self-awareness, and self-knowledge" (Field \& Hoffman, 2007, p. 182). Additional component skills of selfdetermination are "independence, risk-taking and safety skills; self-observation, evaluation, and reinforcement skills; self-instruction; self-advocacy and leadership skills; internal locus of control; [and] positive attributes of efficacy and outcome expectancy" (Wehmeyer, Agran, \& Hughes, 1998, p. 11). Taken together, these skills allow college SWD to seek accommodations to which they are legally entitled, thereby positively shaping their educational experience.

Research suggests that individuals with disabilities who are self-determined can have better post-secondary outcomes, including educational attainment, career goals, social interactions, and independent living status (Adams \& Proctor, 2010; Fiedler \& Danneker, 2007; Field, et al., 2003; Getzel \& Thoma, 2008; Wehmeyer, Field, Doren, Jones, \& Mason, 2004). College SWD in one study identified "capitalizing on student selfdetermination skills" as a factor that enhanced their post-secondary success (GarrisonWade, 2012, p. 117). Similarly, Adams \& Proctor (2010) concluded that "the level or degree of perceived self-advocacy skill does in fact predict student adaptation to college for students with disabilities" (p. 177). Likewise, college SWD identified elements of self-determination as "critical skills that students need to be effective advocates for themselves to secure needed supports and services" (Getzel \& Thoma, 2008, p. 82). Although recognized in the research literature as a significant element of potential for college success, college SWD can often lack self-determination skills.

Research has indicated that lack of self-determination may be a major barrier for college SWD. Many of these students arrived on campus without the necessary selfdetermination or self- advocacy skills that are critical for successful outcomes in college and beyond. Underprepared college SWD were less likely to seek disability support services (Hong, 2015; Marshak et al., 2010) and more likely to experience "negative transitional outcomes after they leave school" (Fiedler \& Danneker, 2007, p. 5). Students who did not genuinely assess their own strengths and weaknesses and did not see themselves as in control of their learning were at risk of poor academic performance. Throughout the literature, self-determination is widely reported as an essential element of post-secondary success for SWD. Acting as the primary agent in one's education is vital. Such skills may be closely associated with identity development.

Identity issues. Abundant research has suggested that college SWD struggle with identity issues, which can negatively impact their post-secondary success. Marshak et al. (2010) found five barriers that prevented college SWD from accessing disability services on campus. One of these barriers, identity issues, consists of "(a) a desire for selfsufficiency, (b) a desire to shed the stigmatized identity they had in high school, and (c) a desire not to integrate the presence of a disability into their college identity" (p. 154). Hong (2015) also reported that college SWD wanted to be independent, yet their desire for self-sufficiency often come at a cost of academic struggles. 
Additionally, "self-stigma" (Stein, 2013) and the "imposter phenomenon" (Denhart, 2008; Lightner et al., 2012) were well documented barriers. College SWD who saw themselves in this negative light sensed that they were "inadequate," felt "guilty" for using accommodations, worried that they were "cheating" the system, and feared that they would be "found out" as "frauds" (Denhart, 2008; Lightner et al., 2012). In short, many college SWD questioned whether or not they deserved to be in college or had the intellectual capacity and skills to succeed in college.

Finally, some college SWD struggled to create a new identity in college. They were anxious to push the "restart button" as they searched for a "new beginning" in an educational setting by not having to deal with being labeled" (Getzel \& Thoma, 2008, p. 77). SWD described college as providing an opportunity to "establish an identity without disability status" (Lightner et al., 2012, p. 150) or to "maintain a 'typical' identity and avoid negative reactions/comments" (Cole \& Cawthon, 2015, p. 170). Such statements indicate that some college SWD believed that their disability defined them and had not yet integrated their disability as part of their overall identity. They often perceived their disability as atypical, something that needed to be hidden or overcome, to ensure "normalcy."

Consequently, some college SWD wanted to shed the stigma of their high school identity. However, trying to create such self-sufficient new identities was not easy and not necessarily helpful for SWD. As Barnard-Brak et al.'s (2010) research indicated, college SWD who avoided discussion about their disability or wanted to be treated like college students without disabilities were less likely to pursue disability services associated with academic achievement and attainment. From one perspective, it may seem that SWD are sabotaging themselves. From another perspective, however, it could appear as though they are acting in their best interest, for to be "normal" in American society is to be successful.

Normalcy, and various derivatives of the term, is a socially constructed concept. It is associated with the ideal norm and is considered the standard by which things are measured. In general discourse, to be normal means to be typical or traditional. In terms of disability, normalcy is associated with non-disabled individuals: people without limitations, impairments, defects, or deficits (Goodley, 2013; Goodley \& Runswick-Cole, 2016; Goodley, Runswick-Cole, \& Liddiard, 2016; Madriaga, Hanson, Kay, \& Walker, 2011). Such a concept is inherently limiting. It restricts notions of what it means to be human, for to cognitively process information differently or to use one arm instead of two implies a person is "abnormal." The concept of normalcy is disempowering, suggesting that individuals with disabilities are less than non-disabled individuals. To speak in terms of normalcy is to marginalize and discriminate against individuals with disabilities.

Critical theorists maintain that society must change its attitudes and actions to be inclusive of all people. Reframing disability as part of the human experience is crucial. As Goodley \& Runswick-Cole (2016) wrote, reconceptualizing disability as "humanness and disability ... acknowledges the possibilities offered by disability to trouble, reshape and re-fashion traditional conceptions of the human" (p. 2). This transforms traditional notions and expectations of personhood. It also shifts the way education functions. For education to be inclusive, socially just pedagogies that focus on students' strengths are 
essential. Such pedagogies oppose "a prevailing sense of normalcy that continues to categorise and divides students" (Madriaga et al., 2011, p. 916). In this environment, accommodations are considered common necessary adaptations that encourage all students to maximize their education experiences, not unique academic adjustments for exceptional students.

Taken together, the literature suggests that identity issues surrounding disability are complicated and complex. Seemingly positive self-perceptions and attitudes (regarding independence, for example) may actually be associated with particular counterproductive behaviors (i.e., not using accommodations) that prevent successful post-secondary outcomes. This is compounded by external challenges that shape, and arguably limit, identity development.

\section{External Challenges}

In addition to internal factors, several external factors commonly emerged in the literature as barriers to college SWD success. Two institutional themes will be discussed here. These include (a) attitudes and actions of faculty members and (b) inappropriate or ineffective accommodations and services. College SWD may be hesitant to disclose their disability or access services if they perceive their instructors and institutions as unsupportive.

Attitudes, actions, and knowledge of faculty. Many college SWD, especially those with invisible disabilities (i.e., specific learning disabilities or emotional disorders), believed they would be perceived as weak or incapable if they disclosed their disability to faculty (Adams \& Proctor, 2010; Couzens et al., 2015; Hong, 2015; Lightner et al., 2012; Stein, 2013). Stein (2013) described this dilemma as "the cost/benefit relationship" (p. 157) of seeking and receiving accommodations, and accessing disability services against the risk of experiencing potential negative stereotypes. "Fear of stigma" prevented some college SWD from advocating for themselves as they "refuse[d] to ask for the accommodations that would ... ease their workload and improve their performance" (Denhart, 2008, p. 493). Some college SWD believed that professors would be disbelieving, unsupportive, or unresponsive. These students described faculty as "cynical and skeptical adults who did not trust them when they claimed they had a disability and needed academic adjustments ... [who] deliberately lower[ed] expectations and embarrass[ed] them in front of the class" (Hong, 2015, p. 222). Research suggests that these fears are not unfounded.

The majority of Denhart's (2008) participants discussed being misunderstood by faculty. This ranged from being seen as "odd" to being considered unintelligent and advised not to take certain classes because of their disability. As participants of GarrisonWade's (2012) study reported, they felt that faculty "saw them as being the problem rather than merely having a problem" (p. 118). Similar negative experiences with professors were frequently cited in the literature. These ranged from professors not understanding how disabilities could impact course attendance, to unwillingness to provide reasonable accommodations, to believing that such adjustments would give college SWD an unfair advantage over their peers without disabilities (Cawthon \& Cole, 2010; Cole \& Cawthon, 2015; Marshak et al., 2010; Sniatecki et al., 2015). 
Research findings indicate that while not all faculty believed college SWD are deficient, many lacked the understanding to make meaningful accommodations for them. Sniatecki et al. (2015) found that faculty had "positive attitudes toward college SWD," believing that they could be "successful and competitive in higher education" (p. 262). Other research clarifies that faculty opinions toward SWD differed based on the disability category. For instance, faculty had most positive attitudes about students with physical disabilities, less positive attitudes about students with learning disabilities, and the least positive attitudes about students with emotional disorders (Sniatecki et al., 2015). Researchers (Garrison-Wade, 2012; Sniatecki et al., 2015) have also identified several knowledge gaps of faculty regarding college SWD, including attendance policies, services provided by the disability services office, and eligibility requirements or procedures for obtaining accommodations (Sniatecki et al., 2015). Similar knowledge gaps of instructors were reported by SWD in Garrison-Wade's (2012) research in which student participants identified "instructor's ignorance [and] lack of training" as barriers to their success (p. 118). Collectively, research suggests that some faculty lack the deep understanding necessary to meaningfully assist college SWD, including knowledge of individual learning differences, particular disabilities, rights of SWD, types of accommodations available, and campus-wide policies and procedures that pertain to college SWD.

Accommodations and disability services. College SWD who qualify under ADA and Section 504 of the Rehabilitation Act can request reasonable accommodations that adjust tasks, procedures, or the environment. Accommodations can apply throughout the college experience, from pre-admission to graduation. Colleges and universities are legally mandated to offer accommodations provided they "do not result in unfair advantage, require significant alteration to the program or activity, result in the lowering of academic or technical standards, or cause the college to incur undue financial hardship" (Thomas, 2000). Furthermore, institutions of higher education must make accommodations in a timely fashion. Accommodations can include changes to classrooms, courses, testing, programs, and other areas.

College SWD must proactively pursue disability services, which is not always easy. Numerous college SWD experienced what we have termed procedural problems, or problems that occur during the process of requesting and securing services. This resulted from complications with evaluations, faculty or institutions not granting accommodations, or delay of service delivery (Black, Weinberg, \& Brodwin, 2015; Cawthon \& Cole, 2010; Marshak et al., 2010). If students are unable to schedule evaluation appointments and are confused by assessment results, they cannot make informed decisions about appropriate accommodations. If students are denied particular services or the necessary services are not provided in a timely manner, they may become frustrated or overwhelmed. In either case, the results may be the same: "abandoned efforts to obtain accommodations and services" altogether (Marshak et al., 2010, p. 160).

For other college SWD, procedural problems were only part of the challenge, as potential barriers to student success occurred after accommodations were provided. For instance, some college SWD reported lack of service monitoring. No office followed up to confirm that the accommodations were used appropriately, to verify that accommodations proved beneficial, or to answer questions and concerns of the student 
(Denhart, 2008). This is crucial information as the effectiveness of disability services depends on their utility.

Accommodations are not meant to be one-size-fits-all. Accommodations that may work for some students within a particular disability category may not be effective for all students within that category. Colleges should not simply offer students "a 'menu' of options based on their disability" but rather tailor services to meet specific educational goals and needs of students (Cawthon \& Cole, 2010, p. 122). In this process, the type and appropriateness of accommodations must be considered. Moreover, colleges and college SWD should remain flexible and willing to adapt to new situations. An effective accommodation for one course (based on the learning environment or content) may not be an effective accommodation for another course. This underscores the importance of accommodation monitoring and individually designed support services. Yet, even effective services can have limitations. College SWD have identified both benefits and challenges of accommodations, particularly in the areas of testing, note taking, multiple and frequent breaks, and technology (Marshak et al., 2010; Stein, 2013). For instance, a note taker who writes illegibly, records incomplete notes, or does not supply notes in a timely manner does not provide a useful service. An ineffective service can hinder student success.

Indeed, other challenges exist that are beyond the scope of this paper. Our intent is not to provide an exhaustive list of challenges in this literature review; rather it is to present an overview of the most frequently discussed internal and external challenges in the literature.

\section{Setting and Participants}

\section{Methodology}

This paper is based on data that resulted from a larger project. Within that context, we designed a qualitative study using a phenomenological approach. For this portion of the project, the phenomenon under study was the experience of college SWD in professional preparation programs. Specifically, our research questions were as follows: What are the internal and external challenges of college SWD in professional preparation programs? What might this mean for practice in higher education?

The project was conducted in 2014-2015 at a public comprehensive college in the northeastern United States that grants primarily baccalaureate degrees and a few master's degrees. We and our colleagues as part of the larger study purposefully selected recruits from seven professional preparation programs, programs that require extensive clinical experiences as they are preparing students to enter field-based professions. Students in these programs were introduced to the study during a class session, and participants volunteered to complete a survey.

In total, 541 participants were recruited and completed the survey. Forty-five participants disclosed having a disability. Of those 45, 37 answered one particular key survey question related to challenges, with 21 providing further written comments. Twelve survey participants volunteered to participate in in-depth semi-structured interviews. The comments and interviews provided the data for this study. 
Table 1 summarizes basic demographic information about those who participated.

\section{Table 1}

Participant Demographics (N=541)

\begin{tabular}{llr}
\hline Category & Self-Identification & Percentage \\
\hline Gender & Female & $85 \%$ \\
& Male & $15 \%$ \\
Race / Ethnicity & White & $86 \%$ \\
& Black/African American & $4 \%$ \\
& Hispanic/Latino & $4 \%$ \\
& Bi/Multi-Racial & $2 \%$ \\
& Asian/Asian American & $1 \%$ \\
& Native American & $<1 \%$ \\
& Other & $<1 \%$ \\
& [no reply] & $2 \%$ \\
Program & Undergraduate & $81 \%$ \\
& Graduate & $19 \%$ \\
& Teacher Education & $37 \%$ \\
& Nursing & $25 \%$ \\
& Communication Disorders \& Sciences & $15 \%$ \\
& Social Work & $11 \%$ \\
& Human Development \& Family Relations & $5 \%$ \\
& Counselor Education & $4 \%$ \\
& School Psychology & $2 \%$ \\
& Others & $1 \%$ \\
\hline
\end{tabular}

Table 2 summarizes respondents who reported disabilities.

Table 2

Reported Disabilities (All) $(n=45) *$

\begin{tabular}{llc}
\hline Category & Self-Identification & Number \\
\hline Gender & Female & 34 \\
& Male & 11 \\
Reported & Specific learning disability & 13 \\
Disability & Other health impairment & 13 \\
& Emotional-behavioural disorder & 7 \\
& Autism spectrum disorder & 3 \\
& Physical impairment & 3 \\
& Hearing impairment & 2 \\
& Speech-language disorder & 2 \\
& Visual impairment & 2 \\
& Traumatic brain injury & 1 \\
& Not known & 3 \\
& [no response] & 3 \\
\hline
\end{tabular}

${ }^{*}$ Six participants selected more than one disability. 


\section{Data Collection and Analysis}

Two pilot surveys were conducted to validate survey questions prior to commencing the study. During the first round, 20 college students not involved in the study completed the initial pilot survey, and then participated in a focus group in which they provided feedback on the construct of the instrument. We and our colleagues asked six questions: (a) What feedback do you have for us about the process, informed consent, and/or survey? (b) Were there any questions or topics you would want us to know more information about or follow up on? Is there more information you would like to share with us? (c) Were any questions confusing and/or redundant? If so, which ones and in what ways? (d) Were any questions powerful, provocative, meaningful? If so, which one and in what ways? (e) What feedback do you have for us on the survey font, length, or organization? (f) Do you have any further feedback for us? We used student responses in combination with a cursory analysis of responses to the initial pilot survey to revise the instrument. The revised pilot survey was completed by 25 new students not involved in the study. Following administration of the revised pilot survey, we asked the same six questions in a focus group format.

Using a cursory analysis of responses in the second pilot survey combined with responses from focus group members, we determined the instrument was ready.

The final survey consisted of nine open-ended and limited-choice questions. Part A contained demographic information. Part B held questions for students with disclosed disabilities, including questions such as:

- Please identify and describe your disability.

- What accommodations or supports have you or do you currently receive at this institution?

- Describe the steps you took to get these accommodations or supports.

- What challenges did you face?

For the purposes of this paper, perspectives on challenges to education were gleaned from survey responses. Survey questions pertained to both internal factors (such as selfadvocacy, relationships with peers, and relationships with faculty) and external factors (consisting of perception of others, course format, content, assignments, fieldwork, and certification or licensure requirements).

The interview questions emerged from existing literature, our own experiences teaching in higher education, and the open-ended survey questions. Prior to interviews, we read and coded surveys, noting where to probe for additional information and clarify statements. We and our colleagues used these notes to elicit detailed responses from participants during interviews. The semi-structured interview was divided into several sections, including specific questions about supports, challenges, and self-awareness. We and our colleagues asked each participant questions from all sections, and then tailored the remainder of the interview session based on newly shared information. The interviews were conducted in person on the school campus at times that were convenient for student participants. The interviews lasted 30-75 minutes and were audio recorded and transcribed verbatim. A copy of the interview transcript was emailed to each 
participant for member checking prior to analysis (Glesne, 2006). Eight participants responded affirmatively, indicating that the transcript adequately captured his or her voice; four participants did not respond.

Data were analyzed using Glaser and Strauss's constant comparative method (Glesne, 2006). We practised coding sample surveys to achieve inter-rater reliability before analyzing final survey data. Interview transcripts were coded several times, initially using descriptive emergent codes then using analytic codes. Codes were organized into a hierarchical coding scheme, which was revised as analysis progressed. Several other steps were taken to enhance the trustworthiness of the study, including triangulation (the use of multiple sources, multiple investigators, and multiple theoretical frames), peer review and debriefing, and clarification of researcher bias via memos and collaborative discussion (Glesne, 2006; Shenton, 2004).

\section{Findings}

\section{Students Who Disclosed a Disability}

Table 3 summarizes respondents' disclosure of disabilities.

Table 3

Reported Disability and Major (for those who elaborated) $(n=21)^{*}$

\begin{tabular}{llc}
\hline Category & Self-Identification & Number \\
\hline Reported Disability & Specific learning disability & 4 \\
& Other health impairment & 13 \\
& Emotional-behavioural disorder & 5 \\
& Autism spectrum disorder & 1 \\
Physical impairment & 1 \\
Hearing impairment & - \\
Speech-language disorder & 2 \\
Visual impairment & - \\
Traumatic brain injury & - \\
Not known & - \\
[no response] & 1 \\
Teacher Education & 10 \\
Nursing & 5 \\
Communication Disorders \& Sciences & - \\
Social Work & 3 \\
Human Development \& Family Relations & 1 \\
Counselor Education & 1 \\
School Psychology & - \\
Speech-Language & 1 \\
\hline
\end{tabular}

* Six participants selected more than one disability.

Three main themes emerged from participants' elaborations. These include (a) selfidentified lack of skills, presenting a barrier; (b) emotions associated with challenges; and (c) lack of understanding. 
Lack of skills. Lack of focus was identified five times by participants as an internal barrier. In open-ended survey responses, this surfaced as "difficulty staying on task" (Participant \#456), "trouble paying attention" (Participant \#74), and "needing to concentrate more" (Participant \#141). Such comments were made regarding fieldwork, face-to-face course structure, and assignments. Likewise, lack of organization was identified five times by participants as an internal barrier. Participants described themselves as being "disorganized" (Participants \#424 \& \#456) and struggling "to keep track of" hybrid and online courses (Participants \#218 \& \#325). In online courses, Participant \#325 "for[got] things, or to go on [to the course delivery platform]." A related issue of time management was identified five times by participants as a challenge. This included problems with "procrastination ... [and] taking timed exams" (Participant \#75), difficulty "completing assignments on-time" (Participant \#218), and attending to the sheer number of assignments (Participant \#308). Such comments primarily pertained to coursework and hybrid course structure.

Emotions associated with challenges. The most common feelings or emotions associated with the challenges identified by participants were fear and insecurity related to self-advocacy. These surfaced in several ways. Some participants worried about how they would be perceived by others. Participant \#313 wrote, "It's hard trying to speak for only one person when everyone seems to be doing okay." In contrast with peers, this participant presumed that other students were succeeding on their own. This may or may not have been reality. By asking for accommodations, this participant potentially would have drawn unwanted attention. Similarly, Participant \#218 revealed, "There is a stigma about using some of the services," and Participant \#269 simply said, "I'm afraid of what others will think." These statements suggest that the emotions connected with disability may be influenced by social settings and public identity. Finally, Participant \#4 described fear of not passing the field experience: "I don't say anything [about my disability] as I'm afraid my field instructor will fail me." Failing a course can significantly impact a student's academic progress. Yet, concealing one's disability status may protect a student from the deficit-based thinking that society often associates with disability. Therein lies the dilemma.

Linked to fear is a sense of insecurity. This surfaced in two ways. First, some participants indicated apprehension in social interactions, including relationships with peers and relationships with faculty. Participant \#63 felt "very awkward and vulnerable at first"; and Participant \#52 reported, "I am never quite sure how well I interact[ed] socially." Feeling unsure of oneself can prevent a student from self-advocating. Participant \#156 described emotional discomfort in and out of class: feeling "selfconscious in class ... [and sometimes did not] participate in out of class activities." The disability led this participant to feel "shy and apprehensive." As another example, Participant \#216 simply said, "It's hard to trust others." These statements suggest that insecurity can limit a student academically and socially.

Insecurity presented differently for other participants who compared themselves to peers without disabilities. Some participants described a perceived imbalance of effort invested by each group. For example, when describing professional behaviors and mindsets, course content, and assignments, Participant \#75 felt jealous of peers without disabilities because of the self-perception of working harder to get good grades and 
taking longer to complete assignments. Other participants described feelings of inferiority. For instance, Participant \#308 wrote, "It's easy to assume others are smarter than myself"; and Participant \#216 stated, "I feel I cannot do much of what they [nondisabled peers] do." Similarly, Participant \#216 explained that it was hard to selfadvocate because of feeling "never good enough." In each of these examples, participants viewed themselves as disadvantaged in comparison to their peers without disabilities.

Stress was another common emotion mentioned by participants as a barrier. As Participant \#195 simply stated, "I feel completely overwhelmed." Other participants identified particular internal and external factors that triggered their stress. For instance, Participant \#216 described a negative cycle between stress and disability. "I get nervous that my condition may worsen and cause trouble with attendance. Stress worsens my condition." Participant \#74 expressed self-doubt: "I feel anxious and hesitant about being capable ... hoping I'm up to graduate speed"; and later shared, "I have anxiety about asking for help for fear of sounding incompetent." Two other participants noted their concerns about certification or licensure requirements. Taking exams was "anxiety-filled" (Participant \#75) and "stressful ... [as] grad school is very competitive" (Participant \#424). According to many participants, stress both exacerbated the challenges associated with disabilities and resulted from living with disabilities in a world that perceives disabilities as a deficit.

Lack of understanding. Lack of understanding presented in two ways. First, several participants indicated that many professors did not understand them or their disabilities. Faculty misunderstanding ranged from skepticism about an existing disability to inability to provide necessary accommodations. As Participant \#74 shared, "Professors and peers [didn't] believe that I have a disability." Participant \#63 wrote, "Sometimes I feel like professors didn't fully understand how difficult the coursework was in conjunction with my disability." Those faculty members who actually believed students when they disclosed their disabilities were not necessarily prepared or willing to make accommodations for them. Participant \#17 explained that many educators did "not give students the proper accommodations." When participants with disabilities were misunderstood, they sometimes took it upon themselves to educate others. For instance, Participant \#75 described the importance of "explaining specific needs to peers and others - explaining ADHD is not just being distracted." Professors' responses to disclosure of disability were described as having affected the student-teacher relationships: "I have withdrawn and gotten closer to professors based on reactions I have received" (Participant \#75). In these instances, lack of awareness and disbelief were associated with strained faculty-student relationships and unproductive learning environments.

Second, some participants acknowledged that they, themselves, lacked understanding. Their misunderstandings primarily emerged from lack of clarity from instructors and course format. Several participants commented on unclear expectations. For instance, Participant \#74 wished that "classes were more planned and explicitly taught and clearer." Participant \#74 also described the challenge of meeting the demands of multiple faculty members when "different professors [had] different and various expectations." Other participants noted the lack of transparency regarding field experience roles and responsibilities. For example, Participant \#313 stated that "instructor expectations sometimes [weren't] really clear, especially on/in the job/field." This was 
echoed by Participant \#135 who claimed, "There was lack of communication in the field." Course format was another frequently mentioned challenge. Specifically, participants identified hybrid or online courses as challenges to their success. For instance, Participant \#75 explained that a hybrid course "allow[ed] for misconception of material and allow[ed] for procrastination." Similarly, Participant \#76 wrote, "I struggled with only written directions" in online courses. Other participants simply stated that they "hated" web-based courses because they were not conducive to their learning. From one perspective, not seeking clarification or not successfully navigating online courses could be viewed as a problem of the learner. The learner did not have the requisite skills to be successful in an online course. From another perspective, this could be seen a problem of poor course design or the delivery platform itself. The system or the instructor created unnecessary barriers. Either way, lack of understanding of course organization and delivery platform lead to student frustration.

\section{Barriers to Accessing Services}

Beyond participants' own beliefs and feelings, external factors influenced their decision not to seek services. These external factors were identified by multiple participants.

Disability Services Office. Five participants indicated that the resources they were provided through the Disability Services Office (DSO) were ineffective or inefficient. One wrote, "I did not pursue any accommodations this semester because that office [disability services] is slow and disorganized" (Participant \#63). In the interview, the same participant elaborated that the DSO was

confused about putting them [books] on a flash drive or scanning it into a PDF for me. They apparently had never done that before because they were like 'Oh, you want an audio book?' I was like, 'No I have no problem with my vision, my sight. I can't hold a huge textbook, and flip pages, and also take notes. I need to have these electronically so I can use them on my computer or iPad. So they said, 'Ok.' And then I would call because they hadn't gotten back to me yet, and they would say, 'Oh, we put them in audio on a flash drive for you.' I said, 'I don't need audio. I told you that!' It was like they didn't get it. ... Even when they did, it was like a month at least into the semester before I got all my books [on a flash drive]. That's a lot of work, a lot of assignments, to catch up on. And they had my books during that time because they had to scan them.

The accommodation provided by DSO was both useless for the student and untimely. Moreover, this example illustrates that DSO did not listen to the student. Given physical limitations, Participant \#63 requested that physical textbooks be scanned and converted into PDFs. However, the participant received audio files of the textbooks.

Participant \#44 also discussed issues with the technology provided by DSO.

When I started college, disability services gave me a PDA [personal digital assistant] to get organized and everything, but for some reason I just never really got with using things like that. I don't know. I never got into the habit of entering things or keeping a calendar or anything like that. 
In this case, a potentially useful tool was provided to the student. However, the student did not see its utility, DSO did not provide training on how to use it effectively, or the tool simply did not match the student's needs. In short, the accommodation was not beneficial.

Inappropriate resources, including technology, were not the only issue. For some participants, human-based academic supports were ineffective. For example, one participant described how tutoring was helpful, but only to a degree. Participant \#11 explained the tutoring experience at DSO as only "helping so much":

They [tutors at DSO] were able to explain in some way how the situation may work-like in a math problem or something with science-and I would be able to understand that. But when it came to the test, it just kind of went away. Disability services didn't really help me in the end.

Tutoring enabled the participant to understand material during the tutoring session, but it did not help the student generalize or maintain that knowledge. This questions the utility of tutoring if the student was unable to apply the information in new settings. Another participant expressed that the studying tips provided by DSO were neither novel nor constructive. DSO “suggested I start color-coding. I said, 'I've been doing that for years.' I know how to teach myself things, and every strategy I have found effective is not working here" (Participant \#207). The participant wanted innovative strategies but did not receive any. Likewise, note taking proved unproductive for Participant \#272, who explained, "I decided not to sign up for note takers anymore because it's not worth it for me. I totally just stopped going there [DSO]." In many cases, ineffective accommodations influenced students' decision to stop accessing disability services altogether.

Faculty. Professors' lack of understanding or preconceived notions of what it means to have a disability also presented barriers to students. For instance, one participant was frustrated by constantly explaining characteristics of the disability to professors. Participant \#272 shared, "The entire time I've been here [at college], the four years, I've had one professor know what dysgraphia is before I talked to them about it." This same participant explained that professors' lack of knowledge prevented them from providing appropriate accommodations. Participant \#272 wrote, "I was not receiving what I needed," elaborating in an interview:

Once I realized that it [dysgraphia] would impact in-class assignments, I talked to professors about it. They're like, "Oh, it's not a big deal. I'll take that into consideration." But nothing. They would always be like, "You need to look over this more." Stuff like that. Well, if I have five minutes to write stuff in class, you're not going to get my best.

Additionally, according to two participants, some faculty did not believe that SWD could be successful in college, specifically in Teacher Education programs. One professor identified a characteristic (forgetfulness) of the student's disability as a weakness. Participant \#325 explained,

I had a professor who one time told me I should maybe think about switching my major because I forget to hand things in.... I know I'm going to be a darn good teacher. I'm $100 \%$ sure of that. It just made me so mad because depression can actually make you lose your memory. 
Similarly, Participant \#272 felt pushed out of the degree program by a faculty member due to the participant's disability.

I was actually told by my advisor that maybe college wasn't cut out for me ... I took a semester off from education courses. I brought my GPA up to a 3.5. I wanted to come back and my advisor told me that it [raising my GPA] was because I was taking easy classes and I didn't have the potential ... So I basically had no choice but to switch [majors].

For several participants, their interactions with and the perceptions of their instructors presented real barriers to their success. In a professional preparation program, academic success is not only linked to degree attainment but also to a career. Students see themselves as future teachers, counselors, nurses, etc. Some faculty members, however, see these students as potential teachers, counselors, or nurses with disabilities (and accompanying deficits).

\section{Discussion and Implications}

\section{Internal and External Barriers}

Students in this study identified internal barriers largely because of a lack of selfdetermination skills and identity issues. As previous research has found, selfdetermination is important, as its component skills positively impact the success of college SWD (Adams \& Proctor, 2010; Getzel \& Thoma, 2008). Many participants described themselves as academically inadequate because of "lack of focus," "lack of organization," and "procrastination." They perceived themselves as less capable as compared to their peers without disabilities, since learning took more effort and time. They also discussed social-emotional hurdles like stress, anxiety, and the stigma associated with disability. This includes self-stigma and public stigma, which is coupled with insecurity and wanting to be seen as "the same" as their non-disabled peers. Factors beyond the participants also affected their experiences in college.

External barriers identified by participants include those related to the DSO and faculty. Participants described unproductive experiences with the DSO. Tutoring provided limited benefits, accommodations were not appropriately matched to studentidentified needs, and several participants ceased DSO support altogether. As Marshak et al. (2010) and Denhart (2008) previously found, many college SWD do not receive adequate accommodations and services from the DSO, which inhibits their success in college. Additionally, negative experiences with faculty adversely affected SWD's outlook and academic success. Respondents explained how faculty pay lip service to their needs without accommodating, theoretically helping the students while simultaneously dismissing their needs in the classroom. Further, participants identified faculty members who attempted to steer them out of majors because of a perceived lack of ability. The findings in this study confirm prior research (Denhart, 2008; Hong, 2015; Marshak et al., 2010; Sniatecki et al., 2015) on faculty influence.

Participants overwhelmingly focused on their skill deficits, particularly within an organizational and motivational frame, as a justification for their struggles. Such negative perspectives are in line with society's archaic and restrictive notions of normalcy. Just 
because a student does not currently demonstrate self-determination, that does not mean he or she cannot become self-determined. Self-determination is not necessarily obvious or innate; it could be systematically and comprehensively taught, modeled, practised, maintained, and generalized. Efficient use of these self-regulation and self-advocacy skills could help decrease the stress and anxiety experienced by college SWD and help shift to a strengths-based approach. In this way, disability could be naturally integrated into students' developing identity, viewed as more of a "diff-ability" than a disability. More importantly, colleges and universities could shift beliefs to accept and expect difference and transform actions to foster inclusion. In doing so, they could anticipate potential barriers and intervene proactively to eliminate these challenges. To be a successful college student does not mean to be a student without a disability.

The internal barriers that college SWD exhibited, combined with the external barriers created by ineffective accommodations provided by the DSO and lack of faculty understanding, converged to create an ineffective learning environment. Poor preparation and ineffective supports ultimately deny college SWD opportunities to succeed in higher education, confirming Dowrick, Anderson, Heyer, and Acosta's (2005) results and reaffirming Magnus and Tøssebro's (2014) conclusions regarding barriers to accommodations. The inability of the institution to support their learning led to college SWDs reporting negative feelings associated with their lack of success in the higher education setting. In a cyclical manner, the combination of internal and external barriers and factors kept college SWD from participating in their college coursework to the best of their abilities, culminating in non-completion of their professional preparation programs in some instances (Dowrik et al., 2005).

\section{Implications for College SWD and Professionals in Higher Education}

College SWD have faced challenges in college for many years. Given that substantial advancements have not been made, it seems that new strategies to support student success may be needed. Although we have not yet implemented the following ideas at our institutions, we believe that they have merit. Stakeholders in professional preparation programs need to re-envision the college learning experience to benefit all students. This could be done at an institutional level through predictive learning analytics, at an academic affairs level by promoting Universal Design for Learning, and at a program level through peer mentoring programs. Though these ideas are not new, they could be applied to professional preparation programs in creative ways.

Predictive Learning Analytics. Although college SWD may face some unique challenges, they are not the only students who could benefit from services. Universal interventions, like providing early assistance, could positively affect the success of all students. (Success may be defined differently from college to college but often refers to GPA, retention rates, and on-time graduation rates.) Student success is important from both an individual and institutional standpoint. Supporting students through graduation helps them obtain degrees and, theoretically, move one step closer to establishing a career. It also reduces attrition rates and helps colleges and universities remain financially solvent. One way to support student success is to use predictive learning analytics. 
Predictive learning analytics collects and analyzes student (behavioural) data, based on its forecasting abilities. This information can then be used to target students who may benefit from both student affairs and academic affairs services (Calvert, 2014; Castellano, 2014; MacMillan \& Green, 2016; MacMillan \& Terry, 2015; Marbouti, Diefes-Dux, \& Madhavan, 2016). Predictive learning analytics epitomizes evidence-based decision making, which most education institutions have embraced. "Actionable data" (MacMillan \& Terry, 2015) "guide strategic decision making" (MacMillan \& Green, 2016). It allows college and universities to better utilize resources effectively and efficiently.

Predictive learning analytics is appropriate for any size institution and at all grade levels. Data can be provided to both instructors and students. Instructors can use the data to inform their interactions with students, suggesting specific strategies to at-risk students. Students can use data to address particular concerns (e.g., a text message reminder to register for courses, pay tuition bills, make an appointment with the writing centre, or make an appointment with the counseling centre). In this way, interventions are tailored to each student and take into consideration contextual variables (Gasevic, Dawson, Rogers, \& Gasevic, 2016). Moreover, predictive learning analytics can be used in conjunction with a campus-wide "early warning system" to have a greater affect on student success (Marbouti et al., 2016, p. 2).

Universal Design for Learning. Using the tenets of Universal Design for Learning and applying differentiated instruction to professional preparation programs can yield fruitful results. The crux of Universal Design for Learning is to provide "multiple means of representation ... multiple means of action and expression ... [and] multiple means of engagement" (National Center on Universal Design for Learning, 2014, paras. 1-3). Centring a college professional preparation program on these standards could create an immersive experience that incorporates student strengths in their final products to show what they know. Examples could include providing multiple modes of input on course assignments. Providing students with choices on how they demonstrate mastery leads to authentic learning experiences and could enable students to develop confidence with coursework and course material. Though professional preparation programs could create a universal-design-based curriculum, they could not avoid the standardized assessments necessary to gain state certification or licensure. Care must be taken to prepare students for certification and licensure exams while simultaneously providing a differentiated learning atmosphere to promote student growth and retention while focusing on local, state, and federal requirements for employment.

Mentoring. Developing a responsive and reflexive professional preparation program hinges on student success. Previously, we have advocated creating an immersive mentoring experience to assuage student reservations toward the college experience and streamline the process to include more authentic learning and sharing experiences (Caruso-Willard, Kiger, Thacker, Countermine, \& Thoma, 2015; Squires \& Countermine, 2017). Drawing on our past experiences developing and conceptualizing mentoring programs for students in a teacher education program, what follows is a framework for including at-risk students (including college SWD) in an authentic mentoring experience to promote success in professional preparation programs. 
Because obstacles may exist for any college student in professional preparation program, a student-centred mentoring experience-with faculty facilitation as necessary-gives students ownership of their learning and places them in leadership positions. This process provides further opportunities for educational growth beyond the traditional classroom experience. As students progress through their professional preparation programs, they shift from learner to participant to mentor.

As implemented by college faculty in the Teaching and Learning Secondary Education program at the Bayh College of Education at Indiana State University (CarusoWillard et al., 2015), beginning in their first year, students are offered opportunities to join the mentoring program. Third- and fourth-year students present the mentoring program in introductory courses to develop relationships with incoming students and become contacts throughout the professional preparation program. As first-year students become involved in the mentoring program, they attend monthly or bi-monthly mentoring meetings to discuss various facets of the professional preparation program with third- or fourth-year students to better navigate the increasing course load and coursework. Participants in the mentoring program rotate up to eventual leadership positions as they enter their third and fourth years. Linking third- and fourth-year students with first-years allows for peer interaction and modeling necessary to create a community of practice (Lave, 1991). Learning from peers creates a situated context that promotes socialization and functions as an opportunity to induct students in a formal or informal learning experience that promotes participation and corresponding success. As students enter their fourth year, they become both mentor and mentee. Linking fourth-year students with recently graduated students participating in the profession gives fourth-years a glimpse at life after school within the profession they have prepared for. Simultaneously, fourthyears continue to mentor third- and second-years to help them navigate the professional preparation program.

Creating a student-centred mentoring program gives mentors and mentees opportunities to create a peer climate of success. With faculty facilitation and encouragement, students could control their educational futures in an authentic way. All students, including at-risk students and college SWD, could benefit from peer support throughout their professional preparation programs. Further, faculty could play an integral role in the planning process while releasing responsibility and its corresponding success to the students involved in the mentoring program.

\section{Limitations and Suggestions for Future Research}

Several limitations apply to this study. First, definitions of survey items (e.g., selfadvocacy, relationships with faculty, course format, and fieldwork) were not provided. Although questions using these terms were validated in the pilot survey, it is possible that participants had differing concepts of the terms and therefore responded from different points of reference.

Second, the number of items in the survey could have contributed to participant fatigue. We noticed that questions toward the end of the survey contained shorter and less detailed responses. On average, participants took 22 minutes to complete the survey. 
Third, this study relies on self-reporting, which may not represent the experiences and perceptions of the entire population of college SWD on campus and thus is vulnerable to the limitations of such research.

However, the purpose of qualitative research is not to capture every voice or present universal truths. Nor is it to produce generalizable findings. As qualitative researchers, our intent is to present rigorous and transparent methodology combined with adequate data and interpretations to enable transferability (Maxwell, 2005; Shenton, 2004). Transferability "invites readers of research to make connections between elements of a study and their own experience" (Barnes et al., 2012). Shenton (2004) explained that "although each case may be unique, it is also an example within a broader group and, as a result, the prospect of transferability should not be immediately rejected" (p. 69). Given these limitations, salient information from our research questions can still be gathered andanalyzed.

\section{Conclusion}

Increasing numbers of SWD are entering college. Like any student entering a new learning environment, some experience transitional challenges. Other students, specifically college SWD, face additional barriers that can hinder their academic success. This is not a new problem. Research in the field has documented this struggle for decades (e.g., Cawthon \& Cole, 2010; Dowrick et al., 2005; Lightner et al., 2012; Magnus \& Tøssebro, 2014). Our findings revealed both internal and external challenges for college SWD. To address these barriers, it is important to understand the complex teachinglearning environment and to implement practices that promote student success and reduce the stigma of disability.

It is imperative for higher education to use effective interventions and supports for all students, not exclusively college SWD. With a broader understanding of disability and broader definition of what it means to be a successful college student, the stigma of accommodations for college SWD may be diverted. Appropriate accommodations are authentic and maximized when they are tailored to student-expressed strengths and needs. This honors the individual learner. Strategies like Universal Design for Learning, peer mentoring, and evidence-based interventions can foster learning communities where all students are supported throughout their college experience. Such practices could bridge the gap between student frustration and academic success. This transformation will likely require institutions of higher education to reframe, reform, and revise the way they think about and approach college SWD.

\section{References}

Adams, K. S., \& Proctor, B. E. (2010). Adaptation to college for students with and without disabilities: Group differences and predictors. Journal of Postsecondary Education and Disability, 22(3), 166-184.

Agarwal, N., Moya, E. M., Yasui, N. Y., \& Seymour, C. (2015). Participatory action research with college students with disabilities: Photovoice for an inclusive campus. Journal of Postsecondary Education and Disability, 28(2), 243-250.

Americans With Disabilities Act of 1990, Pub. L. No. 101-336, 104 Stat. 328 (1990). 
Barnard-Brak, L., Sulak, T., Tate, A., \& Lechtenberger, D. (2010). Measuring college students' attitudes toward requesting accommodations: A national multi-instructional study. Assessment for Effective Intervention, 35(3), 141-147.

Barnes, J., Conrad, K., Demont-Heinrich, C., Graziano, M., Kowalski, D., Neufeld, J. ... Palmquist, M. (2012). Generalizability and transferability. In Writing@CSU. Fort Collins, CO: Colorado State University. Retrieved from https://writing.colostate.edu/guides/guide.cfm?guideid=65

Black, R. D., Weinberg, L. A., \& Brodwin, M. G. (2015). Universal design for learning and instruction: Perspectives of students with disabilities in higher education. Exceptionality Education International, 25(2), 1-26.

Calvert, C. E. (2014). Developing a model and applications for probabilities of student success: A case study of predictive analytics. Open Learning, 29(2), 160-173.

Caruso-Woolard, C., Kiger, S., Thacker, D., Countermine, B., \& Thoma, R. (2015, Summer). Building community: Socialization in the partnership. PDS Partners, 11(1), 8-22.

Castellano, S. (2014). Predicting student success. TD: Talent Development, 68(8), 18.

Cawthon, S. W., \& Cole, E. V. (2010). Postsecondary students who have a learning disability: Student perspectives on accommodations access and obstacles. Journal of Postsecondary Education and Disability, 23(2), 112-128.

Cole, E. V., \& Cawthon, S. W. (2015). Self-disclosure decisions of university students with learning disabilities. Journal of Postsecondary Education and Disability, 28(2), 163-179.

Couzens, D., Poed, S., Kataoka, M., Brandon, A., Hartley, J., \& Keen, D. (2015). Support for students with hidden disabilities in universities: A case study. International Journal of Disability, Development and Education, 62(1), 24-41.

Denhart, H. (2008). Deconstructing barriers: Perceptions of students labeled with learning disabilities in higher education. Journal of Learning Disabilities, 41(6), 483-497.

Dowrick, P. W., Anderson, J., Heyer, K., \& Acosta, J. (2005). Postsecondary education across the USA: Experiences of adults with disabilities. Journal of Vocational Rehabilitation, 22, 41-47.

Fiedler, C. R., \& Danneker, J. E. (2007). Self-advocacy instruction: Bridging the research-to-practice gap. Focus on Exceptional Children, 39(8), 1-20.

Field, S., \& Hoffman, A. (2007). Self-determination in secondary transition assessment. Assessment for Effective Intervention, 32(3), 181-190.

Field, S., Sarver, M. D., \& Shaw, S. F. (2003). Self-determination: A key to success in postsecondary education for students with learning disabilities. Remedial and Special Education, 24(6), 339-349.

Garrison-Wade, D. F. (2012). Listening to their voices: Factors that inhibit or enhance postsecondary outcomes for students' with disabilities. International Journal of Special Education, 27(2), $113-125$.

Gasevic, D., Dawson, S., Rogers, T., \& Gasevic, D. (2016). Learning analytics should not promote one size fits all: The effects of instructional conditions in predicting academic success. Internet and Higher Education, 28, 68-84.

Getzel, E. E., \& Thoma, C. A. (2008). Experiences of college students with disabilities and the importance of self-determination in higher education settings. Career Development for Exceptional Individuals, 31(2), 77-84.

Glesne, C. (2006). Becoming qualitative researchers: An introduction (3rd ed.). New York, NY: Pearson.

Goodley, D. (2013). Dis/entangling critical disability studies. Disability \& Society, 28(5), 631-644. 
Goodley, D., \& Runswick-Cole, K. (2016). Becoming dishuman: Thinking about the human through dis/ability. Discourse: Studies in the Cultural Politics of Education, 37(1), 1-15.

Goodley, D., Runswick-Cole, K., \& Liddiard, K. (2016). The dishuman child. Discourse: Studies in the Cultural Politics of Education, 37(5), 770-784.

Hong, B. S. S. (2015). Qualitative analysis of the barriers college students with disabilities experience in higher education. Journal of College Student Development, 56(3), 209-226.

Individuals with Disabilities Education Act of 1990, Pub. L. No. 94-102, 104 Stat. 1142 (1990).

Lave, J. (1991). Situating learning in communities of practice. In L. B. Resnick, J. M. Levine, \& S. Teasley (Eds.), Perspectives on socially shared cognition (pp. 63-82). Washington, DC: American Psychological Association.

Lightner, K. L., Kipps-Vaughan, D., Schulte, T., \& Trice, A. D. (2012). Reasons university students with a learning disability wait to seek disability services. Journal of Postsecondary Education and Disability, 25(2), 145-159.

MacMillan, J., \& Green, J. (2016). Predictive analytics strategies that promote student success: Using data visualizations to identify struggling students and help them succeed. University Business, 19(8). Retrieved from Questia, https://www.questia.com/magazine/1G1-461068976 /predictive-analytics-strategies-that-promote-student

MacMillan, J., \& Terry, B. (2015). Supporting student success with predictive analytics: Using actionable data effectively can drive strategic decision-making and have a positive impact on both students and institutions. University Business, 18(7). Retrieved from Questia, https://www.questia.com/magazine/1G1-421082227/supporting-student-success-withpredictive-analytics

Madriaga, M., Hanson, K., Kay, H., \& Walker, A. (2011). Marking-out normalcy and disability in higher education. British Journal of Sociology of Education, 32(6), 901-920.

Magnus, E., \& Tøssebro, J. (2014). Negotiating individual accommodation in higher education. Scandinavian Journal of Disability Research, 16(4), 316-332.

Marbouti, F., Diefes-Dux, H. A., Madhavan, K. (2016). Models for early prediction of at-risk students in a course using standards-based grading. Computers \& Education, 103, 1-15.

Marshak, L., Van Wieren, T., Ferrell, D. R., Swiss, L., \& Dugan, C. (2010). Exploring barriers to college student use of disability services and accommodations. Journal of Postsecondary Education and Disability, 22(3), 151-165.

Maxwell, J. A. (2005). Qualitative research design: An interactive approach (2nd ed.). Thousand Oaks, CA: Sage.

National Center on Universal Design for Learning. (2014). The three principles of UDL. Retrieved from http://www.udlcenter.org/aboutudl/whatisudl/3principles

Rehabilitation Act of 1973, Pub. L. No. 93-112, 87 Stat. 355 (1973).

Shenton, A. K. (2004). Strategies for ensuring trustworthiness in qualitative research projects. Education for Information, 22(2), 63-75.

Sniatecki, J. L., Perry, H. B., \& Snell, L. H. (2015). Faculty attitudes and knowledge regarding college students with disabilities. Journal of Postsecondary Education and Disability, 28(3), 259-275.

Squires, M. E. (2015). Balancing the rights of students with disabilities and academic integrity: Case studies for teacher education faculty. In B. A. Burnell \& H. L. Schnackenberg (Eds.), The ethics of cultural competence in higher education (pp. 27-52). Boca Raton, FL: CRC Press.

Squires, M. E., \& Countermine, B. (2017). Power of the heart and limitations of love: Preservice teachers' perceptions of the teaching profession and their implications. In H. L. 
Schnackenberg \& B. A. Burnell (Eds.), Best practices for education professionals (vol. 2, pp. 191-216). Waretown, NJ: Apple Academic Press.

Stein, K. F. (2013). DSS and accommodations in higher education: Perceptions of students with psychological disabilities. Journal of Postsecondary Education and Disability, 26(2), 145-161.

Summers, J. A., White, G. W., Zhang, E., \& Gordon, J. M. (2014). Journal of Postsecondary Education and Disability, 27(3), 245-260.

Thomas, S. B. (2000). College students and disability law. Journal of Special Education, 33(4), 248257. Retrieved from LD Online, http://www.ldonline.org/article/6082/

U.S. Department of Education. (n.d.). Building the legacy: IDEA 2004. Retrieved from https://sites.ed.gov/idea/

Wehmeyer, M. L., Argan, M., \& Hughes, C. (1998). Teaching self-determination to students with disabilities: Basic skills for successful transition. Baltimore, MD: Brookes.

Wehmeyer, M. L., Field, S., Doren, B., Jones, B., \& Mason, C. (2004). Self-determination and student involvement in standards-based reform. Exceptional Children, 70(4), 413-425.

\section{Authors' Note}

Research cited in this article was supported by the Nuala Drescher Award (New York State/United University Professions Affirmative Action Committee). Opinions are those of the author.

We would like to acknowledge the contributions of additional members of our research team (Dr. Heidi Schanckenberg, Dr. Bev Burnell, and Ms. Cindy McCarty).

Correspondence concerning this article should be addressed to Maureen E. Squires, SUNY Plattsburgh, Sibley Hall, 101 Broad St., Plattsburgh, NY, 12901, USA. Email: msqui001@plattsburgh.edu 